\title{
The Linguistic Territoriality Principle - A Critique
}

\section{HELDER DE SCHUTTER}

ABSTRACT In this essay, I develop a critique of the linguistic territoriality principle, which states that, for reasons related to the value of language identity, language groups should be territorially accommodated. While I acknowledge the desirability of implementing a linguistic territoriality principle in some specific cases, I claim that this principle is in general inappropriate for the 'post-Westphalian' linguistic world in which we live. I identify, analyze and reject two distinct justifications for the linguistic territoriality principle: the Linguistic Context justification and the Language Survival justification. Finally, I argue for different means of giving political recognition to the fact that most people value their language as an importance source of identity. This alternative theory sets out to officially recognize multiple languages in a given territory.

The world contains approximately 6000 languages divided into approximately 192 independent states. Virtually all states are multilingual. How should we react politically to this linguistic diversity? What constitutes a just language policy? That is the central question of an emerging field of interest in political theory, increasingly called the 'linguistic justice debate'.

In this essay, I want to critically assess one particular and quite popular language policy option, often called the linguistic territoriality principle. The linguistic territoriality principle (LTP) states that languages should be territorially accommodated, such that on each particular territorial unit only one language group is present or officially recognized. The LTP is believed by many to be the best way to realize linguistic justice. It forms not only part of the glossary of everyday political discourse in multilingual states like Belgium, Canada, Switzerland or Spain, but has also been argued for on linguistic justice grounds in the recent debate on these issues in political theory.

While I acknowledge the desirability of implementing a LTP in some specific cases, in what follows I will criticize this language policy principle, on language identity grounds. The crux of my argument is that the LTP relies on a Westphalian understanding of the relation between states and languages. This understanding does not correspond to the linguistically heterogeneous constellations in which we currently live, and efforts to transform linguistically heterogeneous into linguistically unified territories entail costs that are undesirable from the point of view of justice.

My criticism of the LTP is however not intended as support for the view that languages do not matter from the point of justice and that language groups should not be granted language rights. I believe in the justifiability of language recognition and language rights, and I support the idea that our traditional conception of justice should be supplemented with a linguistic justice branch. However, I do not believe that linguistic territoriality is a convincing articulation of the content of linguistic justice, and in what follows I will outline my grounds for saying that. In my view, the same 
motivation that should induce us to officially recognize languages and grant language rights to their speakers (the belief that languages are important for identity) also gives us reasons to reject the linguistic territoriality principle.

I will proceed in five steps. In the first section, I give a more precise definition of the LTP and I identify three possible versions of it. In the second section, I identify two distinct justifications for the LTP: the Linguistic Context Justification and the Language Survival Justification. In the third and fourth sections, I analyze and reject both justifications successively. In the last section, I summarize what this critique entails for each of the three versions of the LTP, and which alternative understandings of linguistic justice are left open.

Before starting, I should mention that I will not discuss linguistic justice concerns resulting from and related to recent immigration. A discussion of the language rights to which immigrants are entitled no doubt forms an essential part of a full-fledged theory of linguistic justice, but including immigration in this debate would intensify the difficulty of the subject to an enormous extent. I therefore leave this issue for later discussion and concentrate on linguistic justice for settled 'national' language groups — groups of speakers of a language that have not recently immigrated into the state in which they now live, such as the Catalans, the Flemish, the Québécois, the Welsh, the Kurds, etc.

\section{Defining Linguistic Territoriality}

The linguistic territoriality principle appears both in the literature and in practice primarily in three versions. These three versions have in common the guideline that languages and language groups should be territorially accommodated. I will now define each of these separately. This division is based on two general ways of understanding territoriality: on the one hand territoriality can be understood as a principle that stipulates the language regime of a particular region, i.e. the specific language policy, while on the other hand it may be a specification not of the language regime but of who should design this regime, of the authority to design the policy; this second conception has been called the jurisdictional authority form of territoriality. ${ }^{2}$

1. Let us take the language regime understanding first. The LTP as a language regime option has typically been contrasted with a language regime based on the personality principle, which states that individuals carry language rights with them wherever they move. The opposing territoriality principle, then, stipulates that language rights vary from region to region. However, this way of opposing territoriality and personality is potentially misleading (in the absence of a world state), since even the personality language regime has to be instantiated within a particular territory. ${ }^{3}$ Moreover, opposing territoriality and personality in this way still leaves open whether the territoriality regime prescribes institutional monolingualism or also institutional bilingualism (or even multilingualism). In the case of institutional bilingualism, the distinction gets blurred, since, in a sense, the territory is then characterized by a sort of micro-personality.

It is therefore more accurate to understand a territorial language regime as one that stipulates that each territory should contain and/or officially recognize only one language, and is thus characterized by institutional monolingualism, ${ }^{4}$ while the opposing view says that more than one language can be contained and recognized within a given region, such that territories should endorse institutional bi-or multilingualism. 
This is then the first version of the LTP: each territory should contain and/or officially support only one language. The second and the third versions are authority instantiations of the LTP. In opposition to the language regime question, the authority issue is concerned with who should determine this regime, who should have the authority to decide on the language policy. There are essentially two ways in which the issue of authority can be realized on a territorial basis. They differ with regard to the question whether a specific language group is merely entitled to decide its linguistic regime (weak version), or whether it should be allowed to decide more than just linguistic matters (strong version).

2. In the first case, the LTP stipulates that a linguistic-territorial unit should be able to be self-governing as far as this concerns linguistic issues. ${ }^{5}$

3. In the second case, the LTP involves much more and would authorize language groups to be self-governing in much larger domains. A version of this second interpretation, not limited to language groups but concerning groups that are unified both in terms of language and nationality, has been defended by Will Kymlicka, who argues that national language groups are to be granted distinct self-governing political units of their own. For Kymlicka, democratic politics is 'politics in the vernacular', which entails the idea that 'the only form in which genuine democracy occurs is within national boundaries."

In sum, there are three conceptions of territoriality as a normative principle for managing linguistic diversity. The first understanding stipulates that languages and territories are co-terminous, such that each territory contains one language and/or has institutions operating only in that language. The second conception concerns the authority to design language regimes and says that language groups that are territorially based should be self-governing as far as this concerns linguistic affairs. The third conception is also involved with the authority-question and entails that the heart of democratic life should be relegated to the territorial-linguistic unit.

\section{Justifying Linguistic Territoriality}

In this essay, I will evaluate this principle of territoriality on identity grounds, by analyzing whether a concern for linguistic identity should lead us to support or rather reject this principle. There are other grounds on which this principle can be argued for: one might for instance argue that it is desirable for the fluency of democratic deliberation, for social cohesion or for efficiency reasons. But here I will analyze the identity interest in language. In particular, I will criticize those arguments that stipulate that the territoriality principle should be implemented because it is the best way to protect the linguistic identity of individuals. In addition to rejecting the identity arguments for the LTP, I will argue that identity concerns provide an argument against non-identity-related arguments for the LTP.

There are several ways to rely on people's identity interest as a justification for group-differentiated rights such as language rights. In the multiculturalism literature of the past 15 years, two understandings of it are most prevalent. The first, rather straightforward, argument is that individuals derive value from having their identity politically protected and recognized. Let's call this the identity-value argument. The second argument is that membership of a cultural and linguistic community is a crucial 
precondition of individual freedom, since such communities offer us freedom-enabling contexts of choice, which are to be understood as contexts that provide us with choice options and make these meaningful to us. ${ }^{7}$ Let's call this the freedom argument. Theorists like Margalit and Halbertal have invoked the identity-value argument to justify cultural protection, whereas others, like Will Kymlicka and Joseph Raz, have defended minority rights mainly on the basis of the second, freedom view. ${ }^{8}$ Some identity theorists have criticized the freedom argument and have argued that a mere interest in $a$ context of choice is unable to justify a right to people's particular culture. ${ }^{9}$ In what follows, however, I will understand both arguments to be cooperative, in the sense that the freedom argument shows that we need a certain freedom-enabling context, and that identity-value considerations make clear in which specific context my freesdom is enabled. ${ }^{10}$ I will take for granted, without providing an explicit argument, ${ }^{11}$ (i) that language and culture are part of the necessary materials we need to experience freedom and autonomy, and (ii) that people derive value from political recognition of their language and culture. In the remainder of this paper, I will refer to both views taken together as the identity-argument in favour of language rights.

My critical evaluation of the LTP does not concern the use of identity arguments to ground language rights. Rather it focuses on the claim of LTP-enthusiasts that the interest in identity should be realized through a LTP. More specifically, there are two ways in which defenders of the LTP invoke the identity argument to justify the LTP. The first way is the linguistic context justification, which stipulates that to implement the LTP is a requirement of justice since the LTP enables people to conduct their lives in their own linguistic context. The account of the identity interest that this justification presents contains the belief that to respect a language group's identity comes down to assigning a territory to that language group, on which only the language of the group is present and recognized. The second justification is the language survival justification. It argues that accommodating only one language within a certain territory is the only language policy capable of protecting vulnerable languages from disappearance on a particular territory. The idea here is not so much that people have an interest in living within their own linguistic context but rather that people have an (identity) interest in the survival of their language on the territory where they live and that the only way to ensure this is by installing a LTP.

I will now analyze and criticize both justifications taken separately. It should be realized, however, that in many instances or theories, both justifications are appealed to in arguing for the LTP. Especially those exposing the language survival justification will often simultaneously endorse the context justification, arguing that people have both an interest in living within a context in which only their language is present and/or recognized, and in speaking a language that does not run the risk of slowly disappearing on the place where they live.

\section{The Linguistic Context Justification}

I will articulate two counter-arguments against the linguistic context justification for the LTP. The most crucial argument is the hybridity-criticism, which shows what in general is so unsatisfactory about the LTP. The second argument argues that the linguistic context argument claims to reach a greater conclusion that it actually does, 
and that there are other ways to realize its normative appeal than by implementing a LTP. In developing both criticisms, I prepare the ground for a more systematic exploration of how a credible alternative to the LTP might look like, the contours of which will be briefly sketched in the concluding section.

The post-Westphalian hybridity criticism can perhaps best be developed through an analysis of Rawls's conception of peoples and the criticism this conception has received from global justice enthusiasts and multiculturalists. In Theory of Fustice, Rawls has implicitly assumed that the basic unit of justice is the monocultural nation-state, which is unified in terms of language, history and nationality. In due time, Rawls has come to acknowledge that his understanding of this basic unit is an oversimplification, and in his later works he emphasizes that this assumption of a shared language, history and nationality is in many cases unrealistic. But in these later works, he continues to operate on this assumption, in the hope that the political principles generated by the theory may provide guidelines for dealing with more difficult cases:

My hope is that, if we begin in this simplified way, we can work out political principles that will, in due course, enable us to deal with more difficult cases where all the citizens are not united by a common language and shared historical memories. ${ }^{12}$

Although Rawls has explicitly acknowledged that this is an abstraction, this way of proceeding has received much criticism. Global justice theorists like Allen Buchanan, for instance, have argued that 'the populations of states are not "peoples" in Rawls's sense and are not likely to become so without massive, unjustifiable coercion, but rather are often conflicting collections of "peoples" and other groups'. ${ }^{13}$ Buchanan's main claim against Rawls is that Rawls works with the anachronistic assumption that we still live in a Westphalian world. This is the world as represented in the international legal system that grew out of the peace of Westphalia in 1648. According to Buchanan there are two features of a Westphalian world view: '[s] tates are conceived of (1) as more or less economically self-sufficient units ... and (2) as politically homogeneous, unified actors, without internal political differentiation'. ${ }^{14}$ The second feature is the one that concerns us here. In the original Westphalian world-view, it also included a conception of cultural and religious homogeneity. The Westphalian order treated states as unified actors, devoid of intrastate conflicts or pluralism. It affirmed the idea, enunciated in the earlier Peace of Augsburg (1555), that the head of state determines the religion of the people within the state, also better know as the 'cujus regio ejus religio' principle.

Buchanan's ascription of Westphalianism to Rawls's theory is intended as a critique, as he wishes to show that Rawls's Westphalian world has vanished. We don't live in self-sufficient and internally unified states: there is a global basic structure (with global social institutions) and the populations of states are not 'peoples' in Rawls's sense.

Now, while several theorists of multiculturalism and language rights have also criticized Rawls's nation-state assumption and his monocultural conception of peoples, many of them have nonetheless ascribed to what we might identify as the linguistic or cultural analogue of the Westphalian doctrine: a coterminousness of territory and language or culture. In this respect, the linguistic analog of the 'cujus regio ejus religio' principle may be termed 'cujus regio ejus lingua'.

Let me show how this is the case with two prominent theories in the field, the ones developed by Philippe Van Parijs and Will Kymlicka. In a letter to John Rawls dated 
8 May 1998, Van Parijs develops the following objection to an early version of Rawls's Law of Peoples:

[T] here are over 3000 living languages and only 212 sovereign countries to accommodate them. This means that the Law of Peoples' 'standard case' (assuming a simple matching of language and territory) can hardly be the typical case beyond Australia and America, North and South (where minority languages have effectively been driven out, except in Québec). ${ }^{15}$

Yet, despite this criticism of Rawls's empirical assumption about language incidence, on a normative level, Van Parijs does defend a territoriality theory of language policy, compactly summarized by himself as the 'grab a territory' view. ${ }^{16} \mathrm{He}$ defends it by appeal to both the linguistic context justification and the language survival justification. The first justification is present when he argues that linguistic dignity implies that a national group's language has to 'function as the public language of its native speakers' political community.'17 The language survival justification is appealed to as follows: 'To protect vulnerable languages, there is, under circumstances of high mobility, at best one effective strategy, the firm application of the linguistic territoriality principle: Cuius regio, eius lingua. ${ }^{, 18}$ This principle makes the language of a particular territory the only admissible one in that territory as regards (among other things) public administration, political life, judiciary procedures and publicly funded compulsory education.

Likewise, Kymlicka also criticizes Rawls's nation-state assumption for neglecting the fact that many societies have become multinational and multilingual. Kymlicka argues that the problem lies in the fact that Rawls (and Dworkin) 'like most post-war political theorists, work with a very simplified model of the nation-state, where the political community is co-terminous with one and only one cultural community. ${ }^{19}$ In contrast to this, Kymlicka wants to build a political theory for a multinational state.

But, ultimately, it turns out that he defends a very similar congruence between cultural and political as well as territorial units. Kymlicka posits that people live in linguistically unified nations that can be understood as providing contexts of choice that make our life choices and options meaningful to us. Protecting individual freedom thus implies protecting national cultures, since national cultures enable individual choice. He therefore argues that national groups are entitled to self-government rights, to enable their members to maintain their own language and culture. So in Kymlicka's theory, national/linguistic groups get (substantial amounts of) territorial and political autonomy. This proposal thus articulates a linguistic context justification for the LTP: languages and cultures are to be protected because people have significant interests in living within them. More specifically, it not only comes close to the 'monolingual language regime' conception of territoriality but also favours what I described as the third concept of territoriality, since Kymlicka defends the idea that "national" linguistic/ territorial political communities - whether they are unilingual nation-states or linguistically distinct subunits within multination states - are the primary forums for democratic participation in the modern world. ${ }^{20}$

It seems to me that this normative defence of linguistic and cultural rights is grounded in an unrealistically homogeneous concept of language and culture. Kymlicka presents a view of the world as a transparent mosaic of cultural and linguistic blocs, where clear and stable boundaries mark off monolingual national groups. If this starting-point were correct, then a normative monolingual nation-state theory would 
maybe not be inappropriate. In other words, invoking a monolingual nation-state logic may be appropriate as long as the monolingual and monocultural assumption is true of our linguistic and cultural reality. The same may be said with regard to Van Parijs's proposal: the guideline to make 'the language of a particular territory the only admissible one in that territory' proceeds on the assumption that there actually is one language in that territory, and that linguistic and territorial boundaries do overlap.

But this assumption is inappropriate, just as much as Rawls's nation-state assumption was inappropriate in the first place. The issue is not so simple that we could avoid the problem associated with the Rawlsian assumption of one state/one territory/one language for multinational states by assuming there to be more than one monolingual territory within the same state. In many cases, it is not merely the convergence of state and language that is problematic, but also or rather the idea that language and territory are co-terminous. So this assumption is inappropriate. There are certainly many things that do not fit within it and this suggests that it is, more often than not, untrue. The world we inhabit is imbued with multilingualism and linguistic opacity. It is always characterized by vague boundaries, grey zones, minorities within minorities, bi-and multilingualism, etc.

While the territoriality theory with its convergence of linguistic and territorial boundaries is popular, both as a descriptive as well as as a normative theory, upon closer examination, it turns out to rest on a counterfactual conception of language, reminiscent of a Westphalian understanding of our world. This might be termed the transparency concept of language. This conception has three basic features. (1) It understands a language to be spoken by exclusively monolingual speakers. Monolingualism is therefore taken as the standard case. (2) Languages are believed to have transparent boundaries, which gives rise to a mosaic picture of our linguistic world, with neatly juxtaposed languages marked off by clear boundaries. (3) It is assumed that members of a linguistic community are undivided with regard to the issue of identity: individual linguistic identity variation is believed to be very low.

What is particularly important for the argument I am making against the territoriality principle in this context is that relying on this 'Westphalian' transparency view of language and normatively prescribing a territoriality principle may turn out to give rise to instances of injustice. This is due to the fact that basing a normative theory on a monolingual empirical understanding of languages and territories will result in the inability to provide room for instances of linguistic hybridity, such as vague boundaries, cultural overlap, bilingualism, cultural diffusion, diglossia and minorities within minorities. This, in turn, will lead to an inappropriate reduction of our linguistic reality and will squeeze each instance of hybridity into a transparency frame. Multilingual situations, which do not fit into this frame, are then treated as irregularities, to be smoothed away, by monolingual solutions. ${ }^{21}$

This results, first, in a certain inability to provide just and stable solutions to situations in which two or more (ethno)linguistic groups live intermingled, such as in Catalonia, Basque Country, bilingual regions in the Baltic states, Kosovo, Wales and Brussels. ${ }^{22}$ But, secondly, it also results in instances of injustice resulting from the tendency associated with the transparency view to neglect linguistic pluralism or linguistic hybridity. To put this point in a different way: it is not clear why monolingual speakers of monolingual languages are to be picked out as the standard case. Why would it be preferable to expect everyone to linguistically converge on a shared preference of 
monolingual identity feelings? The transparency concept of language, reminiscent of an outdated and Westphalian understanding of linguistic diversity, tends to make the linguistic preferences of some less legitimate than those of others. People with a deviating linguistic attitude (such as those who identify with a language that is not protected as the official language of the territory) or simply bilingual speakers who do not uniquely identify with one of their linguistic belongings are thereby treated as a sort of 'free riders' with illegitimate preferences.

Rather than selecting one group of people and one linguistic identity as the coregroup, the standard case, any concern for linguistic identity will allow and legitimize instances of linguistic pluralism, understood as diversity with respect to how individuals are linguistically embedded and how they experience their linguistic identity. A just theory of language policy will thus try to avoid as much as possible basing itself on one monolingual form of identity, and provide room for linguistic pluralism, with due respect for instances of linguistic hybridity.

We might elucidate this point in a Rawlsian way. The fact of reasonable pluralism, understood by Rawls as a diversity of reasonable comprehensive religious, philosophical and moral doctrines, could for this purpose be extended in such a way as to include a diversity of reasonable linguistic identities. Rawls argues that the fact of reasonable pluralism is not an unfortunate condition of human life. ${ }^{23}$ There is no reason why this wouldn't be true of the diversity of reasonable linguistic identities. This is because exactly the same reasons on which theorists rely who are favourable to the idea of political recognition of language identities can be invoked here. It is the identity interest people have in their own language that forms the justification for language recognition, just with the caveat that we should realize that people may not have a shared understanding of this language identity interest: different people within the same polity and territory may have different language identity interests. Why this debate might benefit from this Rawlsian way of framing it may become clear when we bear in mind the fact that, according to Rawls, a shared understanding on one comprehensive doctrine can be maintained only by the oppressive use of state power and should therefore not be considered as an ideal. ${ }^{24}$ It is this idea that the injustice-argument I just developed tries to demonstrate. ${ }^{25}$

In short, what the argument comes down to is that linguistic contexts are often not monolingual and territorially concentrated, and that members of the same language groups do not always derive the same identity value from their language. The LTP is badly equipped to deal with such cases and can at best conceive of them as disturbing exceptions, whereas in fact they belong to the heart of what linguistic diversity is about.

In addition to the just-mentioned problem of injustice, the context argument has another shortcoming in that it cannot support the conclusion it claims to have reached. This is the second criticism alluded to before. The conclusion, the desirability of the LTP, is reached on the grounds that my language enables my freedom and is valuable to me. The legitimate conclusion that can be drawn from the identity-value and the freedom argument is that individuals need and attach value to their linguistic context of choice and that therefore language contexts ought to be protected and recognized. But that is still different from concluding that I need to live in a territory in which my language is the only language that is protected; it remains to be shown why a policy of linguistic territoriality is desirable. So, while recognition and protection are shown to be desirable, it is not clear why these ought to be realized through the linguistic territoriality principle. 
I will illustrate this point through a short analysis of the implications of Kymlicka's critique of the ideal of linguistic and cultural neutrality for referring to Rawls in this debate. One might object that there is an important limitation in referring to Rawls in this debate, for Rawls's fact of reasonable pluralism of conceptions of the good leads him to an, in the field of language policy, impossible approach that presents the political conception of justice that should be applied to the basic structure of society as a freestanding view. The political conception is 'neither presented as, nor as derived from, [a comprehensive] doctrine. ${ }^{, 26}$ This solution is not completely transferable to the present discussion on linguistic justice since we cannot present the linguistic features of the state's conception of justice as 'freestanding' from any linguistic embeddedness. This is one of the important insights of Kymlicka, who has taught us that the idea of remaining politically neutral towards cultures and languages is impossible: we cannot organize and govern states in a neutral language or in no language at all. ${ }^{27}$ Public institutions like courts and schools cannot operate in no language; they are inevitably linguistically positioned. ${ }^{28}$

But that does not imply that monolingual territoriality is the only feasible alternative. It is one thing to say that a strict separation between state and language is unworkable, but quite another to conclude that the relation between them has to be one-to-one. This would be a simplification: we can think of forms of policy in which the state's linguistic support is not limited to strictly one language. The state cannot avoid taking culturally permeated decisions over the language of public schooling and public services, but it can allow bilingual schools or different schools operating in different languages. We cannot 'replace the use of English in courts with no language', ${ }^{29}$ but we can recognize French alongside English in courts.

In short, while the identity argument can provide a reason for accepting the legitimacy of politically recognizing people's linguistic identities, it is unclear why a LTP conclusion should be thought of as the best way of doing so. It is not clear how the recognition of people's freedom and their wish to obtain language recognition might be compromised by also conferring language recognition on other language groups in the same territory. Now, even if it is thought that granting recognition to other groups will mean less recognition for one's own language group, then there is still no reason to believe that not granting the other language group the same recognition is the best thing to do. The desire to confine language recognition to a single language is an expensive taste, and policies that honour this desire violate principles of equality. ${ }^{30}$

At this point one important remark should be made. There are of course cases where peoples and territories are (predominantly) monolingual and where territorial and linguistic boundaries $d o$ coincide. In general this has come about through nation building: liberaldemocratic states have historically encouraged and 'forced all the citizens on the territory of the state to integrate into common public institutions operating in a common language. ${ }^{31}$

As a result, many Western states are (still) characterized by a neat overlap of language and territory. What this entails is that the transparency concept of language and its related territoriality view of linguistic justice may be appropriate or legitimate at least in these places. But that does not mean that territoriality and linguistic homogeneity should be considered as the ideal in those parts of the Western world in which traces of linguistic hybridity and opacity remain (think of multilingual areas in liberal-democratic states) or in the rest of the world that has not yet been exposed to such linguistic homogenization strategies (think of the myriad of languages in states outside of the 
Western industrialized world). Nor should it mean that we should repress new instances of linguistic heterogeneity whenever these emerge. ${ }^{32}$

\section{The Language Survival Justification}

The language survival justification of the LTP says that monolingual territoriality is the only language policy capable of protecting vulnerable languages from disappearing. This is due to the assimilation pressure more vulnerable languages experience when their speakers come into contact with stronger languages. This defence of territoriality is appealed to by Jean Laponce and by Philippe Van Parijs, who summarizes Laponce's analysis of language contacts as: 'The nicer people are with one another, the nastier languages are with each other. ${ }^{33}$ This linguistic law states that, in cases of contacts between languages, the more powerful language will tend to dominate and assimilate the other(s). This means that the 'free linguistic market', not corrected by means of a choice-restricting LTP, will favour dominant languages and possibly rule out weak and vulnerable languages. The conclusion Van Parijs reaches is that we should care about the survival of vulnerable languages, and that language survival requires the implementation of the LTP.

As this is a defence of territoriality based on identity, it is an important objection to the argument I am developing. But I don't think the objection holds. One way to counter the language survival justification is to repeat the post-Westphalian argument made in the previous section: linguistic identity concerns provide convincing reasons why the LTP is not a desirable way of realizing linguistic protection. The same argument is valid here, because language survival ideals are also grounded in concerns of linguistic identity. Even if language survival might be shown to be an attractive ideal and even if the empirical premise holds that language survival necessarily requires implementing the LTP, then still this reasoning would only hold in a Westphalian mosaic linguistic constellation, where languages are territorially neatly separated and monolingual entities. The fact that we don't live in such a world presents the language survival model with the difficult challenge of finding a realization program that gives equal attention to the identity interests of members of the different language groups that are present on a given territory.

However, there are also good reasons to believe that language survival is not desirable or morally required as an ideal. A second counter-argument against the language survival justification for the LTP states that survival policies may end up being disadvantageous for speakers of such vulnerable languages themselves. Survival goals and policies may not only enable, but in the end also coerce people to maintain their language, for they may entail placing restrictions on those who, out of free will, would decide to linguistically assimilate to another language.

This reply is connected to a larger discussion between instrumental and intrinsic defences of language rights and language protection: whereas the first contends that languages are valuable insofar as they are valued by their speakers, the second view argues that languages have intrinsic importance. Is the language survival justification for the LTP an instrumental or an intrinsic justification? Both are possible. Yet note that the specific language survival justification for linguistic territoriality that I focus on here is one that is grounded in the value individuals experience from having a 
language. This language survival justification of the LTP is therefore instrumental: it is based on the importance of languages for the identity of their speakers, and not on an account of the intrinsic value of languages. ${ }^{34}$

The criticism that implementing the LTP as a mechanism for a language's survival might be detrimental to the interests of its speakers strikes its greatest blow against the intrinsic approach to linguistic justice. But it also strikes at the instrumental account of language survival as a justification for linguistic territoriality, which has trouble explaining why language survival is, after all, a defensible approach, if it turns out that it is hard to defend both the idea that languages ought to be protected from disappearing and the idea that languages are there to benefit their speakers. As soon as a minority of a particular language group starts changing the language from which it claims to derive its identity, the language survival justification loses its normative appeal. Imagine that a certain group of speakers of a weak and vulnerable language A shares a border with speakers of a successful and solid world language B. Imagine further that many current speakers of A value their language to a large extent. Imagine now that the groups interact and that this results in the slow assimilation of A-speakers toward B and that some speakers of A increasingly lose their identity-interest in A and send their children to bilingual schools or to monolingually B-schools. Finally imagine that a generous set of language rights are granted to the speakers of A, including guaranteed representation in parliament, bilingual ballots, subsidized mother-tongue education, hospitals (co-)functioning in A, etc. I don't see anything in this example that might constitute a linguistic injustice, or that might call for urgent political action based on identity concerns. As soon as speakers of A start losing their identity interest in A and increasingly refer to B as their context of choice and identity, the identity argument begins to work toward the benefit of politically recognizing B. In that case, there is no reason to protect $\mathrm{A}$ from gradually eroding. ${ }^{35}$

The basic problem in relying on language survival as a justification for an LTPpolicy is that the actual survival of a language depends not only on the choices of the speakers who value the survival but also on those of others. That is why it is important for the LTP-regime invoked to guarantee survival, that the linguistic liberty of individuals is restricted instead of granted full scope, and that only one language is officially recognized and obtains language rights. If the freedom of individuals to choose a language is respected or if two languages obtain equal recognition, then the 'Laponcemechanism' is set into motion, and the end of this process, the mechanism predicts, is an instance of language loss. But the problem is that the solution to this undesirable outcome infringes on the interests of some - those who don't want survival or have other language identities - in order to giving full scope to those of others - namely those who do want survival. I am not repeating the argument here that the LTP is incompatible with giving equal language rights to the members of another language group who live on the same territory. Rather the argument is that the LTP and linguistic survival policies are incompatible with equal recognition granted to all the members of the same language group the survival of which is thought important.

So the problem with survival policies is that to protect those who wish survival, the choice of those who wish to assimilate must be restricted, and the latter must be forced to remain within their original language. If there is no such restriction, then the vulnerable language may start to disappear. But to use some as means to satisfy the interests of others is clearly an injustice. While there may be a right to speak your own 
language and to receive language recognition, there is no right to have your language spoken by others. ${ }^{36}$ The fact that there is a threshold level of individuals needed to ensure the survival of a language cannot become a reason for forcing others to keep speaking and living within the language.

Perhaps the reply to this will be that the contrast I just sketched between some who wish the survival of the language and others who do not is false. Proponents of this reply will argue that all benefit from the survival; that even those who indicate that they have identity interests in another language, in reality derive their identity interests from their original language. But that is paternalism. We should focus on the identity that people indicate they want, rather than on the judgement of others. Since identity is at stake here, which in contrast to, for instance, objectively assessable factors like income is necessarily dependent on what people who have the identity believe or feel themselves, it is morally unacceptable to decide on the identity interests of others. What should count is what people want, not what others think they want or should want. Even if the result is that the survival opportunities of the language that some would want to preserve are considerably undermined, we should acquiesce in it, for the alternative - repressing and restraining the identity of some in order to support the identity of others - is worse in terms of morality.

In short, the satisfaction of the identity interests of some speakers of a language should not lead to the restriction of the identity interests of other speakers of the same language who increasingly derive their identity from another language. There seems to be no reason, then, to see language survival as a requirement of justice, and therefore it is hard to see how it can constitute a justification for the LTP.

The upshot of the position I developed against language survival is that, once the background requirements of linguistic justice are appropriately fulfilled and generous language rights are granted, there is no injustice involved in language loss. Once linguistic justice is realized, one might regret the loss of a language in the same way that one might regret that Albert Camus did not live longer (or that he hadn't worked harder) so that he might have written more novels. There may be a loss involved in the fact that a language disappears, but that loss is not unjust. If people, under circumstances of overall (including linguistic) justice, increasingly derive their identity interest from another language than their original one, then it is not a requirement of justice to prevent that from happening. This argument is made more convincing by realizing that, once background conditions of linguistic justice are realized, language loss normally occurs as a result of the choices of individuals. As Bernard Spolsky puts it, ' $[\mathrm{w}]$ hatever blame may reasonably be attached to language policies and social, economic, religious and political forces, it seems that the loss of linguistic diversity results less from linguistic genocide than from linguistic suicide. ${ }^{37}$

There is in principle nothing wrong with assimilation from one language to another. (It is rather the prevention of assimilation that is morally problematic.) This does not mean that striving for the survival of one's own language, as an individual, is morally illegitimate. There is a category of morally legitimate actions in between immoral and morally required actions, and the individual pursuit of language survival (e.g. through writing in that language or arguing against the use of certain languages in shops or advertising) should best be understood to belong to this category. Attempts to guarantee the survival of a specific language are morally equivalent to attempts to raise interest for Greek mythology or to make korfball a more popular sport. 


\section{Summarizing the Alternatives}

In this paper I have argued against the territoriality-principle on identity grounds. While I have attempted to clear the ground for a more satisfactory alternative theory of linguistic justice, I haven't developed this alternative here. Yet I think that my argument does define the contours within which such an alternative theory should operate. In closing, I will briefly outline these contours, by indicating what my critique of the LTP entails for the three conceptions of territoriality I have outlined at the outset.

The first language-regime conception of territoriality maintains that each territory ought to have a monolingual language regime, such that territorial and linguistic boundaries should coincide and/or that in each territorial unit, only one language receives officially recognition. I have argued that the neat coincidence between languages and territories is far from being the standard case and that implementing a LTP in cases without such coincidence would require infringing upon the identity of both linguistic minorities and of people whose linguistic identity is characterized by instances of linguistic hybridity. What this means is that in general, for linguistic justice to be realized, it suffices that, in multilingual regions, rights to an institutional recognition of one's language are granted to the speakers of each language. This implies a preference for the opponent personality principle, and a correlated bilingual institutionalism.

Note, however, that the personality principle itself can accommodate many features of the Westphalian transparency concept of language. Many individuals might still think of themselves as monolingual beings with monolingual identity interests. While I don't think there is any reason to force such individuals to adopt a more hybrid linguistic identity, I believe that we should be wary of the reverse situation, where people with hybrid attitudes (such as bilinguals) are squeezed in monolingual frames. To avoid this, we can think of ways to accommodate such bilingual or hybrid linguistic attitudes. Bilingual or bicultural schools, hospitals and political parties may provide examples of this.

The second, jurisdictional conception of territoriality maintains that linguisticterritorial units should be able to be self-governing as far as this concerns linguistic issues. There are two ways in which this ought to be nuanced. First, and somewhat off the point, one might point to the fact that, increasingly, norms of linguistic justice are being codified by supranational and 'supralinguistic' units of linguistic regulation. In this respect, the past decade has seen a rise in international codes and conventions that stipulate the protection of linguistic and cultural identities. The European Framework Convention for the Protection of National Minorities is a relevant case. ${ }^{38}$ This internationalization of language rights standards may entail a restriction for the idea of full linguistic sovereignty.

Secondly and more relevantly to the present discussion, while forms of self-government are to a large extent to be realized in territorial units, linguistic identity considerations point to the fact that these territorial units will not and should not be monolingual, both in its empirical meaning (there is only one language present) and in its policy sense (only one language is recognized). This implies that forms of bilingual co-self-government over linguistic issues will have to be pursued. Some forms of linguistic self-government may also be pursued, such as self-government on cultural centres for a particular language. But linguistic self-government should not be 'total' in the sense that all language policy issues will be decided on by the language group itself. The language 
in which the state's parliament functions and in which the national anthem is sung, for instance, cannot be decided on by one language group internally, but should be the subject of discussion in a decision-making process that involves both language groups.

The third conception of territoriality argues that monolingual territories should be self-governing and stipulates that territorial national/linguistic units form the relevant units for democratic deliberation and decision-making. Although this statement may be appropriate in many cases, linguistic identity considerations suggest that territories are often not monolingual and that making them so may be unfeasible and undesirable. So identity considerations provide a counterargument against restricting democracy to monolingual units.

Helder De Schutter, Katholieke Universiteit Leuven, Centre for Ethics, Social and Political Philosophy, Parkstraat 45 - bus 3602, B-3000 Leuven, Belgium. Helder.DeSchutter@hiw.kuleuven.be

\section{Acknowledgements}

This essay is based on my contribution to a review seminar on Philippe Van Parijs's forthcoming book entitled Linguistic fustice for Europe and for the World, which took place on December 12, 2005 in Leuven, within the KULeuven-UCL Seminar in Philosophy and Social Policy. I wish to thank the participants to this seminar, and in particular David Robichaud, Toon Vandevelde and Philippe Van Parijs. Many thanks also to Alan Patten and Nenad Stojanovic for their very helpful comments.

\section{NOTES}

1 See especially Philippe Van Parijs, Linguistic fustice for Europe and for the World (Oxford: Oxford University Press, forthcoming). See also D. Réaume \& L. Green, 'Bilingualism, territorialism, and linguistic justice', The Network: Newsletter of the Network on the Constitution, 1, 3 (1991): 9-11. For a general overview of the linguistic justice debate, see W. Kymlicka \& A. Patten (eds.), Language Rights and Political Theory (Oxford: Oxford University Press, 2003).

2 See Alan Patten, 'What kind of bilingualism?', in Kymlicka \& Patten op. cit., pp. 300-02; Denise Réaume, 'Beyond personality: The territorial and personal principles of language policy reconsidered', in Kymlicka \& Patten op. cit., pp. 274-78.

3 Réaume op. cit., pp. 275-76.

4 Strictly speaking, there are two versions of this. The first is simply that territories should have a monolingual language policy. The second goes further and argues that, besides institutionalizing monolingualism at each territory, territories and language groups should coincide, such that each language group has a territory of its own, and each territory contains one language. The two versions differ to the extent that a pure version of the first conception might still be compatible with the existence of different language groups on the same territory, who are nonetheless submitted to a language policy that favors one of them (see, for instance, J. Laponce, Langue et Territoire (Québec: Presses de l'Université Laval, 1984); Réaume op. cit., pp. 276-277; Van Parijs, Linguistic Fustice for Europe and for the World op. cit.).

5 Jurisdictional territoriality can also refer to the idea 'that the rules of language to be applied in a given situation will depend solely on the territory in question' (see K. McRae, 'The principle of territoriality and the principle of personality in multilingual states', International fournal of the Sociology of Language 4 (1975): 33-54). But as argued above (with regard to the first conception of territoriality), this may make the distinction analytically useless, since every policy depends on the territory in which it is designed. I therefore understand jurisdictional territoriality as referring to the fact that the self-governing territory is inhabited by one language group (Réaume, op. cit., p. 275). 
6 W. Kymlicka, Politics in the Vernacular. Nationalism, Multiculturalism and Citizenship (Oxford: Oxford University Press, 2001), p. 325, see also p. 213; W. Kymlicka, 'Territorial boundaries: A liberal egalitarian perspective' in D. Miller and S. H. Hashmi (eds.) Boundaries and Fustice. Diverse Ethical Perspectives (Princeton, NJ: Princeton University Press, 2001), pp. 249-275.

7 W. Kymlicka, Multicultural Citizenship. A Liberal Theory of Minority Rights (Oxford: Oxford University Press, 1995), p. 83.

8 A. Margalit \& M. Halbertal, 'Liberalism and the right to culture', Social Research 61, 3 (1994): pp. 491510; Kymlicka, Multicultural Citizenship op. cit.; J. Raz, 'Multiculturalism: a Liberal Perspective', Dissent 41, 1 (1994): 67-79.

9 Margalit \& Halbertal op. cit.

10 This is also the view that Kymlicka ultimately takes, when he argues that identity considerations provide a basis for specifying which culture will provide the relevant context of choice (Kymlicka, Politics in the Vernacular op. cit., p. 55, n.7).

$11 \mathrm{My}$ question in this essay is not whether the identity-value and the freedom argument are true, but whether, if they are true, the linguistic territoriality principle is what follows. Proponents of the LTP answer this question positively. I will provide a negative answer, showing the fallacies implied in the positive answer and articulating an alternative understanding of the normative consequences of the identityvalue and the freedom argument.

12 J. Rawls, Law of Peoples (Harvard: Harvard University Press, 1999), pp. 24-25.

13 A. Buchanan, 'Rawls's Law of Peoples: Rules for a Vanished Westphalian World', Ethics 110, 4 (2000): $697-712$ at p. 701 .

14 Buchanan op. cit., p. 701.

15 J. Rawls \& P. Van Parijs, 'Three letters on The Law of Peoples and the European Union', Revue de philosophie économique 7, 3 (2003): 7-20 at p. 11.

16 P. Van Parijs, 'Europe's linguistic challenge', European fournal of Sociology 45, 1 (2004): 113-154 at p. 141.

17 P. Van Parijs, 'Linguistic justice as equal dignity', paper presented at the Katholieke Universiteit Leuven on December 12, 2005, to be published as chapter 4 of Van Parijs' forthcoming Linguistic Fustice for Europe and for the World, p. 18.

18 P. Van Parijs, 'The ground floor of the world. On the socio-economic consequences of linguistic globalisation', International Political Science Review 21, 2 (2000): pp. 217-233 at p. 219.

19 W. Kymlicka, Liberalism, Community and Culture (Oxford: Clarendon Press, 1989), p. 177.

20 Kymlicka, Politics in the Vernacular op. cit. p. 213.

21 An example here would be Van Parijs's suggestion for a last shift of the linguistic border in Belgium, which would remove any remaining language facilities for linguistic minorities in border communities, see P. Van Parijs, 'Natievorming tegen solidariteit?', Samenleving en Politiek. Tijdschrift voor een democratisch socialisme 10, 6 (2003): pp. 27-35.

22 In such constellations, there are often linguistic minorities that are not enough territorially concentrated to be able to claim a territory of their own (such as the Flemish in Brussels). The LTP cannot provide a just solution to such groups. We might require them to move to other places where their language might be spoken or to simply linguistically assimilate, but doing so may be impossible when the rationale to grant language rights in the first place was respect for people's identity. Forcing minorities to change their language or place of residence is to subsidize the identity interest of some while infringing on those of others.

23 J. Rawls, Political Liberalism (New York: Columbia University Press, 1996), p. 144.

24 Ibid., p. 37.

25 Note that, in making this Rawlsian point, I am not trying to equate having a language with having a conception of the good life. The only thing the Rawlsian route should elucidate here is that there may be diverse ways of being linguistically embedded and that this diversity is legitimate.

26 Rawls, Political Liberalism op. cit., p. 12.

27 Kymlicka, Multicultural Citizenship op. cit., p. 108.

28 For a defence of 'linguistic neutrality' that takes account of the impossibility of political detachment of linguistic issues, see A. Patten, 'Liberal Neutrality and Language Policy', Philosophy E Public Affairs 31, 4 (2003): 356-86.

29 Kymlicka, Multicultural Citizenship op. cit., p. 110.

30 There may be one sort of argument that might be developed for granting more recognition to one group among others. If there is a sudden and sharp decline in the number of speakers of a language, then some 
of its remaining non-assimilating members might face important cost in terms of their freedom. (See Patten, 'What kind of bilingualism?' op. cit..) In such relatively rare cases, perhaps giving temporary priority to one language can be justified. But even then there is no reason for not also recognizing other language groups to some extent as well.

31 Kymlicka, Politics in the Vernacular op. cit., p. 1.

32 Compare: 'democratic states that still have an open future [with regard to the development of distinct linguistic communities] have every reason for pursuing the course that leads to a linguistically homogeneous polity, B. Barry, Culture and Equality. An Egalitarian Critique of Multiculturalism (Cambridge: Polity Press, 2001), p. 228.

33 Van Parijs, 'The ground floor of the world' op. cit., p. 219.

34 For an intrinsic argument seeA. W. Musschenga, 'Intrinsic Value as a Reason for the Preservation of Minority Cultures', Ethical Theory and Moral Practice 1, 2 (1998): 201-225. For a rejection of intrinsic arguments, see Kymlicka, Multicultural Citizenship op. cit., p. 214, n. 24.

35 I should make clear that I assume that this example operates against the background of a society that satisfies conditions of overall justice, including linguistic justice. So people enjoy the right to speak their own language and to have it politically recognized. In a sense, assuming this begs the question of what linguistic justice comes down to. I will come back to this question in the concluding section.

36 The case for special state subsidies for opera might provide an interesting analogy here. While liking and attending opera performances is very legitimate, and while perhaps a successful argument might be made that special state subsidies should be awarded to the opera business, there is no right to insist that others like and attend opera. The difference between the opera and the linguistic case is of course that while opera may exist without a (large) audience, a language can't: a language needs a critical mass of speakers to ensure its survival. But it remains the case that it is unjust to create or maintain that critical mass through restricting the choices of those who don't want the good of the language for the benefit of those who do want it.

37 B. Spolsky, Language Policy (Cambridge: Cambridge University Press, 2004), p. 216.

38 See also The Universal Declaration of Linguistic Rights (UNESCO, 1996) and the Declaration on the Rights of Persons Belonging to National or Ethnic, Religious and Linguistic Minorities (UN, 1992). 